\title{
Tonic Dopamine Induces Persistent Changes in the Transient Potassium Current through Translational Regulation
}

\author{
Edmund W. Rodgers, ${ }^{1}$ Wulf-Dieter C. Krenz, ${ }^{1}$ and Deborah J. Baro ${ }^{1,2}$ \\ ${ }^{1}$ Department of Biology and ${ }^{2}$ Neuroscience Institute, Georgia State University, Atlanta, Georgia 30303
}

Neuromodulatory effects can vary with their mode of transmission. Phasic release produces local and transient increases in dopamine (DA) up to micromolar concentrations. Additionally, since DA is released from open synapses and reuptake mechanisms are not nearby, tonic nanomolar DA exists in the extracellular space. Do phasic and tonic transmissions similarly regulate voltage-dependent ionic conductances in a given neuron? It was previously shown that DA could immediately alter the transient potassium current $\left(I_{\mathrm{A}}\right)$ of identified neurons in the stomatogastric ganglion of the spiny lobster Panulirus interruptus. Here we show that DA can also persistently alter $I_{\mathrm{A}}$, and that the immediate and persistent effects of DA oppose one another. The lateral pyloric (LP) neuron exclusively expresses type $1 \mathrm{DA}$ receptors (D1Rs). Micromolar DA produces immediate depolarizing shifts in the voltage dependence of $L P I_{\mathrm{A}}$, whereas tonic nanomolar DA produces a persistent increase in LP $I_{\mathrm{A}}$ maximal conductance $\left(G_{\max }\right)$ through a translation-dependent mechanism involving target of rapamycin (TOR). The pyloric dilator (PD) neuron exclusively expresses D2Rs. Micromolar DA produces an immediate hyperpolarizing shift in $\mathrm{PD} I_{\mathrm{A}}$ voltage dependence of activation, whereas tonic DA persistently decreases PD $I_{\mathrm{A}} G_{\max }$ through a translation-dependent mechanism not involving TOR. The persistent effects on $I_{\mathrm{A}} G_{\max }$ do not depend on LP or PD activity. These data suggest a role for tonic modulators in the regulation of voltage-gated ion channel number; and furthermore, that dopaminergic systems may be organized to limit the amount of change they can impose on a circuit.

\section{Introduction}

By and large, neurons communicate using wired or volume transmission (Zoli et al., 1998; Fuxe et al., 2007). Wired corresponds to classical fast synaptic transmission, whereas volume transmission is characterized by paracrine release and modulator diffusion. Dopaminergic neurons use volume transmission and fire tonically with intermittent bursts (Dreyer et al., 2010; Ford et al., 2010). This results in nanomolar concentrations of dopamine (DA) in the extracellular space that can locally and transiently increase to micromolar levels during neuronal bursts (Zoli et al., 1998). Phasically released DA produces transient, temporally relevant alterations in neuronal circuits, whereas tonic DA has a permissive function. Deficits caused by lesions to the dopaminergic system can be rescued through tonic administration of DA agonists (Schultz, 2007). The molecular mechanisms underpinning the actions of tonic DA are not well studied.

DA acts via two basic types of G-protein-coupled receptors (GPCRs), type 1 DA receptors (D1Rs) and D2Rs (Yao et al.,

\footnotetext{
Received May 2, 2011; revised July 16, 2011; accepted July 19, 2011.

Author contributions: E.W.R., W.-D.C.K., and D.J.B. designed research; E.W.R. and W.-D.C.K. performed research; E.W.R., W.-D.C.K., and D.J.B. analyzed data; E.W.R. and D.J.B. wrote the paper.

This work was supported by NIH Grant DA024039 to D.J.B. We thank Timothy Dever and Kimilia Kent for excellent technical assistance.

The authors declare no competing financial interests.

Correspondence should to be addressed to Deborah J. Baro, Neuroscience Institute, Georgia State University, Atlanta, GA 30303.E-mail: dbaro@gsu.edu.

DOI:10.1523/JNEUROSCI.2194-11.2011

Copyright $\odot 2011$ the authors $\quad 0270-6474 / 11 / 3113046-11 \$ 15.00 / 0$
}

2008), to rapidly and transiently alter the biophysical properties of ion channels (Harris-Warrick et al., 1998; Surmeier et al., 2007). Many GPCRs, including DA receptors, can also persistently modulate ionic conductances through translation using target of rapamycin (TOR) and/or MAPK pathways (Smith et al., 2005; Hoeffer and Klann, 2010; Musnier et al., 2010; O’Dell et al., 2010; Sossin and Lacaille, 2010; White and Sharrocks, 2010). We speculated that the persistent effects of tonic nanomolar DA might be mediated through translation.

The stomatogastric nervous system (STNS) (see Fig. 1) is a well characterized model for studying neuromodulation (Marder and Bucher, 2007). It comprises multiple central pattern generators, including the 14 neuron pyloric network. We previously showed that dopaminergic systems in the STNS and mammalian CNS are similar: both use volume transmission (Schultz, 2007; Oginsky et al., 2010) and the same transduction pathways (Clark and Baro, 2006, 2007; Clark et al., 2008; Oginsky et al., 2010). In both systems, DA receptors (DARs) are concentrated on/near synaptic structures involved in wired transmission (Shetreat et al., 1996; Wong et al., 1999; Yao et al., 2008; Oginsky et al., 2010; Zhang et al., 2010). Mammalian DARs may segregate to specific synapses (Goto and Grace, 2005, 2008), and D2Rs are localized to only $40 \%$ of all synaptic structures on an identified STNS neuron (Oginsky et al., 2010).

The transient potassium current $\left(I_{\mathrm{A}}\right)$ is transiently regulated by DA in a variety of cells and systems (Harris-Warrick et al., 1998; Hoffman and Johnston, 1999; Perez et al., 2006). $I_{\mathrm{A}}$ is encoded by shal $(\mathrm{Kv} 4)$ channels, operates at subthreshold mem- 
A

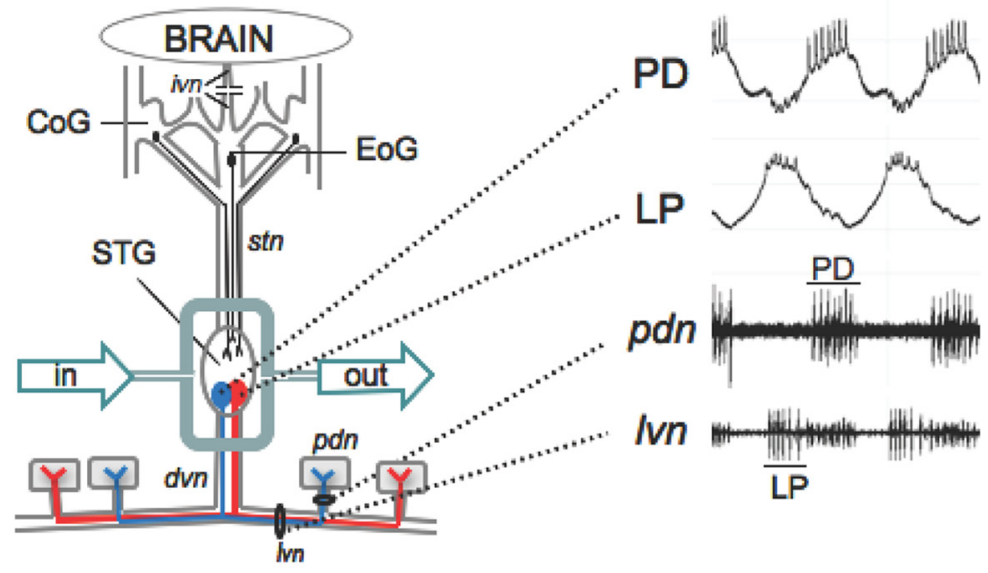

B

Control

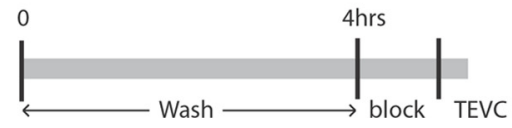

Figure 1. Experimental preparation and protocol. $\boldsymbol{A}$, The STNS was dissected and pinned in a Sylgard dish. This severed the inferior ventricular nerve (ivn), the only source of descending input from the brain as well as sensory inputs (data not shown). The STG was isolated with a Vaseline well. Saline, with or without drugs, was continuously superfused into the well. Neurons in the commissural ganglia ( $\mathrm{COG}$ ) and the esophageal ganglion (EoG) project to the STG (e.g., filled circles) via the stn, and these projections remained intact until neurons were voltage-clamped at the end of the experiment. The two filled circles within the STG represent PD and LP motor neurons, 3 of the 14 cell pyloric network, within the 30 cell STG. Both neurons project axons through the $d v n$ and the Ivn. The pyloric dilator nerve $(p d n)$ exclusively contains axons from the two PD neurons, and synapses with the PD muscles (shown as gray boxes). $\boldsymbol{A}$, Right, An example of $L P$ and PD somatic intracellular and extracellular recordings obtained from one experiment. Cells in all experiments were unambiguously identified through correlations between the intracellular (top two traces) and extracellular (bottom two traces) recordings (location of extracellular electrode indicated by black line). $\boldsymbol{B}$, General diagram of the experimental design. The end of cell identification marked time 0 . At this point, DA was immediately applied for $1 \mathrm{~h}$ in the experimental preparations. At time 1-4h, DA was washed out with Panulirus saline. Control experiments were continuously superfused with Panulirus saline from time $0-4 \mathrm{~h}$. At time $4 \mathrm{~h}$, a sucrose block was applied to the stn and the STG was superfused with blocking saline for $1 \mathrm{~h}$, after which $\mathrm{I}_{\mathrm{A}}$ was measured with TEVC.

brane potentials, and plays an important role in neuronal function by regulating excitability, spike timing and frequency, dendritic integration and plasticity, and the phasing of neurons in rhythmically active networks (Harris-Warrick et al., 1998; Hoffman and Johnston, 1999; Perez et al., 2006). The immediate effects of micromolar DA on $I_{\mathrm{A}}$ have been well characterized for all pyloric neurons (Harris-Warrick et al., 1995a,b; Kloppenburg et al., 1999; Peck et al., 2001). Here we studied two pyloric neurons to examine whether or not DA could persistently modulate $I_{\mathrm{A}}$ through translation.

\section{Materials and Methods}

Animals. California spiny lobsters, Panulirus interruptus, were purchased from Don Tomlinson Commercial Fishing, Catalina Offshore Products, and Marinus Scientific, and were housed in saltwater aquaria at Georgia State University (Atlanta, GA). Animals were a mix of males and females.

Pharmacology. All drugs were purchased from Sigma-Aldrich, unless otherwise noted. All drugs were administered to the stomatogastric ganglion (STG) via superfusion by peristaltic pump. DA was administered for $1 \mathrm{~h}$ in all cases. To minimize oxidation, DA was made fresh and exchanged after $30 \mathrm{~min}$. Antagonists, and translational and transcriptional inhibitors were administered $10 \mathrm{~min}$ before DA for all experiments. Dosages for translational inhibitors [ $30 \mu \mathrm{M}$ anisomycin (Anis), 10 $\mu \mathrm{M}$ cycloheximide (CHX), and $100 \mathrm{~nm}$ rapamycin] and transcriptional inhibitors [50 $\mu \mathrm{M}$ actinomycin D (ACD), $100 \mu \mathrm{M}$ 5,6-dichloro-1- $\beta$ D-ribobenzimidazole (DRB)] were chosen to be greater than or equal to previously demonstrated effective dosages in several invertebrate species. The DAR receptor antagonists were initially applied according to previously determined dosages and increased as necessary (Zhang et al., 2010).
STNS dissection, pyloric cell identification. Lobsters were anesthetized on ice for at least 30 min, followed by an STNS dissection, as previously described (Selverston et al., 1976). The STNS was pinned in a Sylgard-lined dish. The STG was desheathed, and during this process a portion of the juxtaposed stomatogastric nerve $(s t n)$ was also desheathed. A Vaseline well was constructed around the STG and the juxtaposed $s t n$ and dorsal ventricular nerve $(d v n)$. The well was continuously superfused for the remainder of the experiment (Fig. 1A). Using a Dynamax peristaltic pump (Rainin), the STG was superfused with Panulirus saline as follows (in mM): $479 \mathrm{NaCl}, 12.8 \mathrm{KCl}, 13.7 \mathrm{CaCl}_{2}, 39$ $\mathrm{Na}_{2} \mathrm{SO}_{4}, 10 \mathrm{MgSO}_{4}, 2$ glucose, 4.99 HEPES, 5 TES, pH 7.4. For overnight experiments, the STNS was placed in a culture media (Panchin et al., 1993) consisting of the following (final concentration): $1 \times$ Panulirus saline, $0.5 \times \mathrm{L} 15$ Leibovitz medium, 200U/L penicillin/streptomycin (ATCC), and $0.1 \mathrm{mg} / \mathrm{L}$ neomycin. This results in a slightly hypertonic medium, which does not cause any deleterious effects on the preparation.

The entire experiment was performed at room temperature. Temperature was continuously monitored with a miniature probe in the bath. The temperature changed by $<1^{\circ} \mathrm{C}$ throughout the course of the day (the change ranged from 0.1 to $0.9^{\circ} \mathrm{C}$ on any given day), and by only $3^{\circ} \mathrm{C}$ across all experiments $\left(19-22^{\circ} \mathrm{C}\right)$.

Cells were identified using previously described standard intracellular and extracellular recording techniques. Intracellular somatic recordings were obtained using $20-40 \mathrm{M} \Omega$ glass microelectrodes filled with $3 \mathrm{M} \mathrm{KCl}$ and Axoclamp 2B or 900A amplifiers (Molecular Devices). Extracellular recordings of identified motor neurons were obtained using a differential AC amplifier (A-M Systems) and stainless steel pin electrodes. Pyloric dilator (PD) and lateral pyloric (LP) neurons were identified by their distinct waveforms, the timing of their voltage oscillations, and correlation of spikes on the extracellular and intracellular recordings (Fig. $1 B$ ).

Two-electrode voltage-clamp. A portion of the stomatogastric nerve was desheathed and isolated in a Vaseline well. Descending inputs were removed with a sucrose block applied to the well for $1 \mathrm{~h}$. At this point, the STG was superfused continuously with blocking saline, which consisted of Panulirus saline containing picrotoxin $\left(10^{-6} \mathrm{M}\right)$ to block glutamatergic synaptic inputs and the following voltage-dependent ion channel blockers: tetrodotoxin (TTX; $100 \mathrm{nM}, I_{\mathrm{Na}}$, sodium current), tetraethylammonium $\left(20 \mathrm{mM}, I_{\mathrm{K}(\mathrm{V})}\right.$ and $I_{\mathrm{K}(\mathrm{Ca})}$, voltage-gated potassium current and calcium-dependent potassium current, respectively), cadmium chloride (200 $\mu \mathrm{M}, I_{\mathrm{Ca}}$, calcium current), and cesium chloride $\left(5 \mathrm{mM}, I_{\mathrm{h}}\right.$, hyperpolarization-activated current). LP and PD cells were penetrated with two low-resistance microelectrodes (5-9 M $\Omega$ ) filled with $3 \mathrm{M} \mathrm{KCl}$. The holding potential was $-50 \mathrm{mV} . I_{\mathrm{A}}$ activation was measured using 12 sweeps in which a $200 \mathrm{~ms},-90 \mathrm{mV}$ prepulse was followed by a series of depolarizing steps $(500 \mathrm{~ms}$ ) ranging from -40 to $+60 \mathrm{mV}$ in $10 \mathrm{mV}$ increments. $I_{\mathrm{A}}$ was further isolated by digitally subtracting the leak current, which was determined using the same activation protocol without the $-90 \mathrm{mV}$ prepulse. After subtraction, the peak current was converted to conductance $\left[G=I_{\text {peak }} /\left(V_{\mathrm{m}}-E_{\mathrm{k}}\right)\right]$, where $G=$ conductance, $I_{\text {peak }}=$ peak current, $V_{\mathrm{m}}=$ membrane voltage, and $E_{\mathrm{k}}$ is the reversal potential for potassium, and fit using a first-order Boltzmann equation to determine the voltage of half activation and maximal conductance. Steadystate inactivation was measured by a series of sweeps that varied over the range of the $200 \mathrm{~ms}$ prepulse from -110 to $-20 \mathrm{mV}$ in $10 \mathrm{mV}$ increments 
followed by a constant step to $20 \mathrm{mV}$ (500 ms). Again to further isolate $I_{\mathrm{A}}$, a digital subtraction of the leak current was performed. In this case, leak current was determined by subtracting a depolarizing prepulse to $-20 \mathrm{mV}$, followed by a test pulse to $20 \mathrm{mV}$. Peak current was again converted to conductance and fit with a firstorder Boltzmann equation to derive voltage of half-inactivation.

Experimental design. The STNS was dissected, and the STG was continuously superfused with Panulirus saline (Fig. 1A). The spontaneous motor output of the pyloric network was monitored throughout the experiment with extracellular electrodes on the lateral ventricular nerve $(l v n)$ and the pyloric dilator nerve $(p d n)$ (Fig. 1A). PD and LP neurons were identified. To examine the persistent effects of DA, we then applied either $5 \mathrm{~nm}$ or 5 $\mu \mathrm{M}$ DA to the STG for $1 \mathrm{~h}$ (Fig. $1 B$ ). Control preparations received saline during this time. In both DA-treated and control conditions, this was followed by $3 \mathrm{~h}$ of saline wash, unless otherwise indicated. After the wash, the ganglion was prepared for two-electrode voltageclamp (TEVC) by applying a sucrose block to the $\operatorname{stn}$ and perfusing the ganglion with blocking saline for $1 \mathrm{~h}$. The sucrose block and blocking solution disrupted descending input to LP and PD neurons, prevented the spontaneous oscillations in membrane potential and spiking activity normally observed in LP and PD, and prevented spike-evoked and graded glutamatergic transmission within the STG. $I_{\mathrm{A}}$ in LP and PD neurons was subsequently measured with TEVC. The limitation of this approach is that it does not allow for the comparisons of $I_{\mathrm{A}}$ before and after treatment within an individual preparation. However, this limitation is offset by the fact that to obtain a measurement at $t=0$, spontaneous rhythmic activity would need to be disrupted before DA application. This could trigger homeostatic and/or compensatory mechanisms that might confound the interpretation of results.

Quantitative real-time PCR. Electrophysiologically identified LP and PD somata were physically removed from the STG as previously described (Oginsky et al., 2010). The ganglion was incubated with 1.2 $\mathrm{mg} / \mathrm{ml}$ collagenase type IA (Sigma-Aldrich) until the cells were amenable to extraction with a fire-polished micropipette. Cells were immediately placed on dry ice and stored at $-80^{\circ} \mathrm{C}$ until reverse transcription. $\mathrm{LP}$ and PD cells were processed for RT-PCR by using a modification of the cellsto-cDNA kit (Ambion). First, $9 \mu$ l of lysis buffer was added to the cell and incubated at $75^{\circ} \mathrm{C}$ for $10 \mathrm{~min}$. Next, $0.2 \mu \mathrm{l}$ of DNasel was added to the lysis buffer and incubated for $15 \mathrm{~min}$ at $37^{\circ} \mathrm{C}$, and then again at $95^{\circ} \mathrm{C}$ for an additional $5 \mathrm{~min}$ for inactivation. RNA was then reverse transcribed as per the manufacturer's instructions. After reverse transcription, the cDNA was precipitated using the following protocol (Liss, 2002): $1 \mu \mathrm{g}$ of glycogen, 250 ng of polyC RNA, $250 \mathrm{ng}$ of polyC DNA, 1/10 volume $2 \mathrm{M}$ sodium acetate, and 3.5 volumes $\mathrm{EtOH}$ were added to the $\mathrm{cDNA}$, incubated overnight at $-20^{\circ} \mathrm{C}$, centrifuged at maximum for $60 \mathrm{~min}$, washed with $70 \% \mathrm{EtOH}$, and centrifuged again for $15 \mathrm{~min}$. The pellet was then dried and resuspended in $13 \mu \mathrm{l}$ of sterile water, and incubated for $60 \mathrm{~min}$ at $45^{\circ} \mathrm{C}$ before quantitative PCR.

Specific Taqman primers for Panulirus shal were designed using primer express 3 (Applied Biosystems), forward: 5' -ACGTTAGGATACGGCGAC ATG, reverse 5'-CACACGCCACCCACAATCT, and VIC-labeled probe 5' TCCCCACACGCCCACGGG. FAM labeled Eukaryotic 18 S rRNA probes were used as the endogenous control (Applied Biosystems). All reactions were run in triplicate, with $2 \mu \mathrm{l}$ of cDNA in each reaction. Assays were run with Jumpstart Taqready mastermix (Sigma-Aldrich), on an Applied Biosystems Fast 7500 Real-Time PCR machine, using the following parameters:
$2 \mathrm{~h}$ at $95^{\circ} \mathrm{C}$ for one cycle, $15 \mathrm{~min}$ at $95^{\circ} \mathrm{C}$, and $1 \mathrm{~h}$ at $60^{\circ} \mathrm{C}$ for 50 cycles. Assay efficiencies were determined by serial dilution. Data were analyzed via $t$ test of relative quantity $\left(\mathrm{RQ}=2^{-\Delta \Delta \mathrm{Ct}}\right)$.

Statistical analysis. Data were checked for normal distribution and analyzed using parametric statistical tests with Prism software package (Graphpad). Significance was set at $p<0.05$ in all cases. Means are followed by SDs unless otherwise indicated. Individual samples that were $>2$ SDs from the mean were excluded from the analysis. There are two electrically coupled PD neurons in each ganglion, and they have been shown to have highly correlated $I_{\mathrm{A}}$ transcript levels (Schulz et al., 2006). As such, only one cell per preparation could be used for analysis, because of these cells not being independent samples. In the cases where two cells were subjected to TEVC, we simply included the lower maximal conductance $\left(G_{\max }\right)$ value of the two.

\section{Results}

The immediate and persistent effects of DA on LP $I_{\mathrm{A}}$ are opposed

LP expresses D1Rs, but not D2Rs (Zhang et al., 2010). A range of 5-100 $\mu \mathrm{M}$ DA produced an immediate decrease in the peak LP $I_{\mathrm{A}}$ through a protein kinase A (PKA)-dependent mechanism (Harris-Warrick et al., 1995b; Zhang et al., 2010). The persistent effects of DA on LP $I_{\mathrm{A}}$ have never been examined. We designed an experiment to determine whether nanomolar or micromolar concentrations of DA persistently altered LP $I_{\mathrm{A}}$ (see Materials and Methods, Experimental design) (Fig. 1). A $1 \mathrm{~h} 5 \mathrm{nM}$ or $5 \mu \mathrm{M}$ DA administration followed by a $3 \mathrm{~h}$ wash significantly increased the peak LP $I_{\mathrm{A}}$ relative to controls (Fig. $2 A)$. This persistent increase was not due to a shift in the voltage dependencies of activation or inactivation, as there were no significant differences among control, $5 \mathrm{nM}$, or $5 \mu \mathrm{M}$ treatment groups (ANOVA, $p>0.05$ ) (Fig. 2 B; Table 1). On the other hand, LP $I_{\mathrm{A}}$ in both DA-treated groups showed a 


\begin{tabular}{llrr}
\hline & Control & 5 nм DA & $5 \mu \mathrm{MDA}$ \\
\hline $\mathrm{LPV}_{1 / 2}$ activation & $-10.73 \pm 1.14(n=6)$ & $-6.097 \pm 3.11(n=5)$ & $-9.00 \pm 2.58(n=8)$ \\
$\mathrm{LPV}_{1 / 2}$ inactivation & $-61.59 \pm 1.75(n=5)$ & $-58.32 \pm 1.31(n=5)$ & $-62.71 \pm 2.34(n=5)$ \\
$\mathrm{PDV}_{1 / 2}$ activation & $-14.86 \pm 1.3(n=7)$ & $-14.98+1.03(n=5)$ & $-16.1 \pm 2.14(n=6)$ \\
$\mathrm{PDV} V_{1 / 2}$ inactivation & $-60.41 \pm 1.06(n=5)$ & $-61.36 \pm 0.4(n=4)$ & $-60.86 \pm 1.42(n=5)$ \\
\hline
\end{tabular}

Values are given as the mean \pm SEM for the voltages of half activation and voltages of half inactivation for both LP and PD under three treatments. Data were fit using first-order Boltzmann equation and were analyzed by ANOVA. There were no significant differences within cell type with respect to DA treatment. $V_{1 / 2}$, Voltage of half.

A

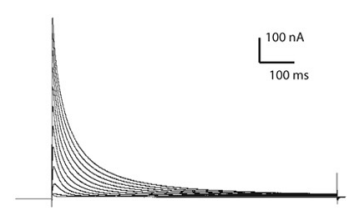

Control

B

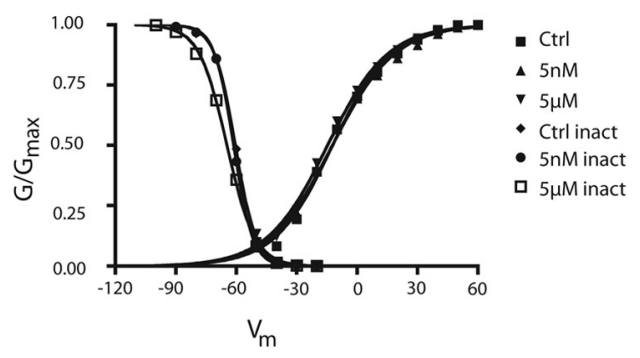

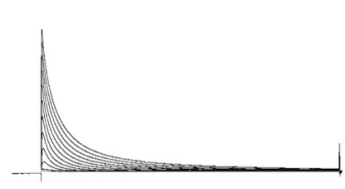

5nM Dopamine

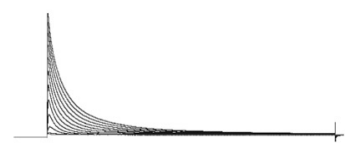

$5 \mu$ M Dopamine

\section{C}

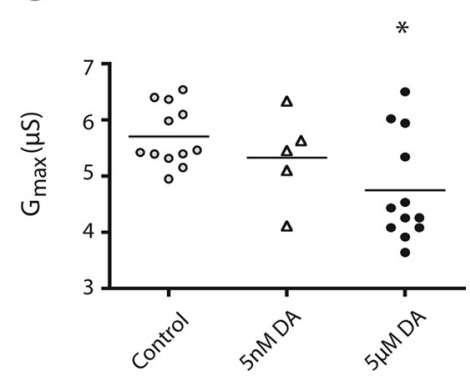

Figure 3. A $1 \mathrm{~h}$ administration of DA produces a persistent decrease in $\mathrm{PD} / \mathrm{A}$ Gmax. $A$, Representative $\mathrm{PD} / \mathrm{A}$ for the experiments diagrammed in Figure 1C. Leak subtracted PD current traces elicited by a series of depolarizing steps from a hyperpolarizing prepulse using TEVC, as described in Materials and Methods. $\boldsymbol{B}$, Normalized activation and inactivation curves for the three treatment groups ( $n \geq 5$ per data point). There were no significant differences with respect to voltage dependence generated by DA treatment. C, Tonic activation of PD D2Rs persistently decreased PD $I_{A} G_{\max }$. Each symbol represents $P D I_{A} G_{\max }$ measured with TEVC in one experiment. Data were analyzed using a one-way ANOVA with Tukey's post hoc test. *Significantly different from saline control group. Ctrl, Control.

significant $\sim 25 \%$ increase in average $G_{\max }$ compared with controls (ANOVA, $F_{(2,23)}=7.09, p=0.004$; Tukey's post hoc test, $p<0.01$ for $5 \mathrm{~nm}$ vs control, $p<0.05$ for $5 \mu \mathrm{M}$ DA vs control) (Fig. 2C). The DA-induced increase in LP $I_{\mathrm{A}} G_{\max }$ could be blocked by $25-40 \mu \mathrm{M}$ flupenthixol (Flu), which was previously shown to be an effective antagonist for pyloric D1Rs and D2Rs ( $t$ test, DA vs Flu plus DA; $t_{(11)}=2.122, p=0.029$ ) (Zhang et al., 2010). It should be noted that higher concentrations of the antagonist were required to block the persistent versus immediate effects of DA.

DA administration produced a significant, persistent elevation in LP $I_{\mathrm{A}} G_{\max }$ relative to controls, but $I_{\mathrm{A}} G_{\max }$ was only measured at the end of the experiment. Without knowledge of the initial values for $I_{\mathrm{A}} G_{\text {max }}$, we could not assess which group changed relative to time 0 . Did $I_{\mathrm{A}} G_{\max }$ increase in the DA-treated groups and/or decrease in the control group over the course of our experiments? To examine this issue, we compared LP $I_{\mathrm{A}} G_{\max }$ measurements obtained from the 4 h experiments described here to those obtained from a previous study (Zhang et al., 2010) where LP $I_{\mathrm{A}}$ was measured with TEVC immediately after cell identification (termed "Acute" group in Fig. $2 C ; n=41$ ). Consistent with previous reports (Schulz et al., 2006), acute measurements showed a wide range of values for $I_{\mathrm{A}} G_{\text {max }}$. Both DA treatments restricted $I_{\mathrm{A}} G_{\max }$ to the upper range of the acute distribution. Both DA treatment groups were significantly different from the acute population (ANOVA, $F_{(3,61)}=8.235, p=$
0.0001; Tukey's post hoc test, $p<0.01$ for both $5 \mu \mathrm{M}$ and $5 \mathrm{~nm}$ vs acute). If we assume that at $t=0$ the DA treatment groups demonstrated the same range as the acute group, then DA either increased or maintained $I_{\mathrm{A}} G_{\max }$, depending upon its initial value. Control $4 \mathrm{~h}$ preparations were not significantly different from the acute group (Tukey's post hoc, $p>0.05$ ), suggesting that control values for $I_{\mathrm{A}} G_{\max }$ did not change in a consistent fashion over the course of our experiments.

In summary, $5 \mathrm{nM}$ and $5 \mu \mathrm{M}$ DA persistently increased $I_{\mathrm{A}} G_{\max }$ by $\sim 25 \%$. This persistent effect opposes the immediate action of DA on LP $I_{A}$, which is to shift the voltage dependence of activation and inactivation in the depolarizing direction, thereby decreasing the peak $I_{\mathrm{A}}$ activated across the physiological range of depolarizing potentials (Harris-Warrick et al., 1995b; Zhang et al., 2010). The threshold concentration for the immediate effect was $\sim 1 \mu \mathrm{M}$ in our hands (Zhang et al., 2010), which was at least three orders of magnitude higher than the saturating concentration for the persistent effect (note that the $5 \mathrm{nM}$ and $5 \mu \mathrm{M}$ DA effects were similar in magnitude).

\section{The immediate and persistent effects of DA on PD $I_{A}$ are opposed}

PD neurons express D2Rs, but not D1Rs (Oginsky et al., 2010). Acute application of high concentrations of DA increases $I_{\mathrm{A}}$ within seconds (Kloppenburg et al., 1999). The persistent effects of DA on PD $I_{\mathrm{A}}$ were unknown. We therefore performed the same experimental paradigm, as follows: $1 \mathrm{~h} 5 \mathrm{~nm}$ or $5 \mu \mathrm{M}$ DA bath application (Panulirus saline for controls) followed by a $3 \mathrm{~h}$ wash, a $1 \mathrm{~h}$ block, and finally TEVC to measure PD $I_{\mathrm{A}}$ (Fig. 1). DA produced a persistent decrease in the peak PD $I_{\mathrm{A}}$ (Fig. $3 A, C$ ). As was the case in LP, the DA-induced change in the peak $I_{\mathrm{A}}$ was not due to significant alterations in $\mathrm{PD} I_{\mathrm{A}}$ voltage dependencies (ANOVAs, $p>0.05$ ) (Fig. $3 B$; Table 1). Instead, $I_{\mathrm{A}} G_{\max }$ was significantly decreased in $5 \mu \mathrm{M} \mathrm{DA}(\sim 20 \%)$, but not $5 \mathrm{nM} \mathrm{DA}-$ treated preparations. (ANOVA, $F_{(2,26)}=5.064, p=0.014$; Tukey's test, $p<0.05$ for $5 \mu \mathrm{M}$ ) (Fig. $3 C$ ). This DA-induced decrease in $I_{\mathrm{A}} G_{\max }$ was blocked by the application of $100 \mu \mathrm{M}$ metoclopramide (Met) $\left(t\right.$ test, DA vs Met + DA, $t_{(18)}=1.92, p=$ 0.035 ), which was previously shown to be a specific antagonist for pyloric D2Rs (Zhang et al., 2010). Again, higher concentrations of the antagonist were required to block the persistent versus immediate effects of DA.

In sum, the immediate and persistent effects of DA on PD $I_{\mathrm{A}}$ were opposed, as was the case for LP. One hundred micromolar 
DA produced an immediate increase in PD $I_{\mathrm{A}}$, whereas $5 \mathrm{~nm}$ and $5 \mu \mathrm{M}$ DA persistently reduced the peak $\mathrm{PD} I_{\mathrm{A}}$ relative to control by decreasing PD $I_{\mathrm{A}} G_{\max }$, but only the $5 \mu \mathrm{M}$ effect was statistically significant. Notably, both the persistent and immediate effects of DA were opposed for D1Rs versus D2Rs.

\section{The $5 \mu \mathrm{M}$, but not $5 \mathrm{nM}$, DA-induced} changes in $I_{\mathrm{A}}$ persist for $24 \mathrm{~h}$

We next asked whether the DA-induced changes in $I_{\mathrm{A}} G_{\max }$ persisted beyond $4 \mathrm{~h}$ and up to $24 \mathrm{~h}$. We followed a similar experimental procedure, except that the $1 \mathrm{~h}$ DA application was followed by a $1 \mathrm{~h}$ wash and then the preparation was placed in culture media overnight, and $I_{\mathrm{A}} G_{\max }$ was measured the following day $(18-24 \mathrm{~h}$ after DA administration) (Fig. 4A). The persistent effect of $5 \mu \mathrm{M}$ DA on LP $I_{\mathrm{A}} G_{\max }$ was maintained over this extended time course (38\% increase), but $5 \mathrm{~nm} \mathrm{DA}$ was not significantly different (ANOVA, $F_{(2,16)}=4.652$, $p=0.028$; Tukey's test, $p<0.05$ for $5 \mu \mathrm{M}$ compared with control) (Fig. $4 B$ ). At 24 h, PD $I_{\mathrm{A}} G_{\max }$ was still significantly reduced by $23 \%$ in $5 \mu \mathrm{M}$ DA preparations relative to controls $\left(t_{(9)}=2.602, p=0.029\right)$ (Fig. $\left.4 C\right)$.

\section{DA-induced changes in $I_{\mathrm{A}}$ do not} depend on LP or PD activity

In our experimental conditions, the pyloric circuit is spontaneously active and produces a rhythmic motor output until blocking saline and the stn block were applied before TEVC (Fig. 1C). DA can cause immediate alterations in LP and PD activity, and the threshold for this effect is $\sim 10^{-6} \mathrm{M}$ at $12-$ $14^{\circ} \mathrm{C}$ (Flamm and Harris-Warrick, 1986). Since the immediate and persistent effects of DA are opposed, it is possible that the persistent changes in $I_{\mathrm{A}} G_{\max }$ represent a homeostatic/compensatory response to the immediate DA-induced changes in target neuron activity. To determine whether this was the case, we performed the same experimental paradigm but included 100 nM TTX from time -10 min to $1 \mathrm{~h}$ to block neuronal activity during $5 \mu \mathrm{M}$ DA administration (Fig. 5A). TTX prevented action potentials and oscillations in membrane potential (Fig. 5B), and at TTX resting membrane potentials (average LP, $-59 \pm 5$ $\mathrm{mV}, n=10$; average $\mathrm{PD},-52 \pm 4 \mathrm{mV}, n=$ 10) graded transmission will be negligible (Johnson and Harris-Warrick, 1990; Johnson et al., 1995). Under these conditions, DA still produced a significant increase in LP $I_{\mathrm{A}} G_{\max }\left(\right.$ ANOVA, $F_{(3,25)}=4.072, p=$ 0.018; Dunnett's test, DA and TTX + DA $p<0.05$ compared with saline control) (Fig. 5C) and a significant decrease in $\mathrm{PD} I_{\mathrm{A}}$
A

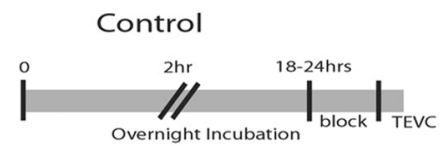

DA-treated

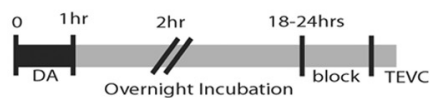

B

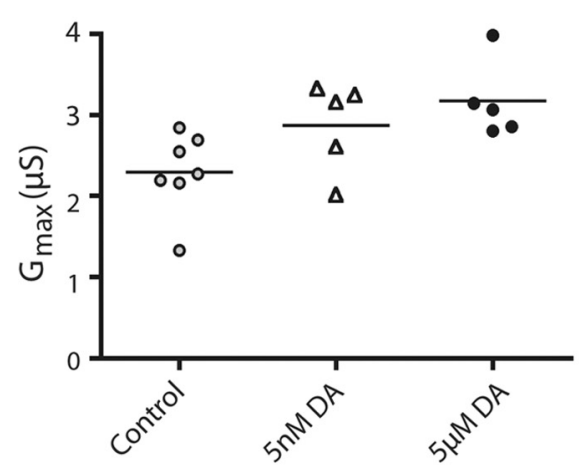

C

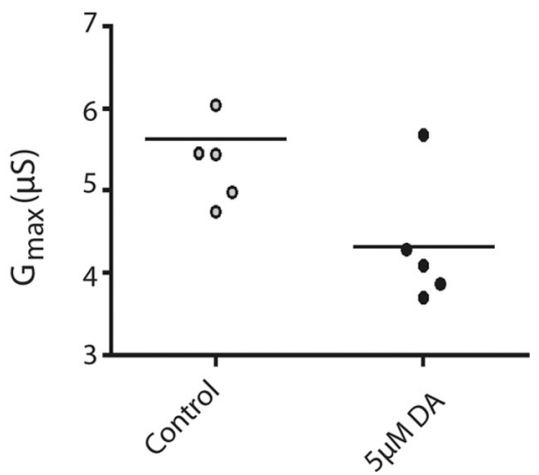

Figure 4. DA effects on $I_{\mathrm{A}}$ persisted for $24 \mathrm{~h}$ in both cell types. $\boldsymbol{A}$, Timeline for overnight experiments: DA was applied for $1 \mathrm{~h}$ followed by a $1 \mathrm{~h}$ wash with Panulirus saline; the preparation was then incubated overnight in culture media (see Materials and Methods), and $I_{A}$ was measured with TEV (he following day. Control experiments were the same except that they were constantly superfused with Panulirus saline for the first $2 \mathrm{~h}$. $\boldsymbol{B}$, The persistent effect of tonic activation of LP D1Rs on $I_{A}$ is time and dose dependent. Each symbol represents $L P I_{A} G_{\text {max }}$ measurements from a single experiment. Data were analyzed with a one-way ANOVA followed by a Dunnett's post hoc test. * Significant differences from control. C, Tonic activation of PD D2Rs with $5 \mu \mathrm{m}$ DA persistently decreases $I_{\mathrm{A}}$ for at least $24 \mathrm{~h}$ under our experimental conditions. Each symbol represents $P D I_{\mathrm{A}} G_{\max }$ measurements from a single experiment. Data were analyzed with a one-way ANOVA followed by a Tukey's post hoc test. *Significant differences from control.

A
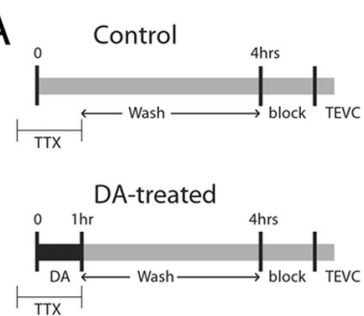

C

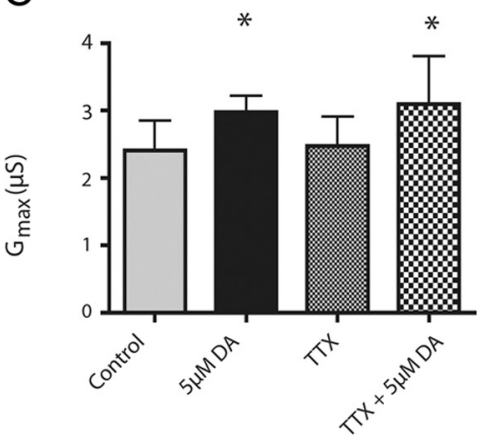

B

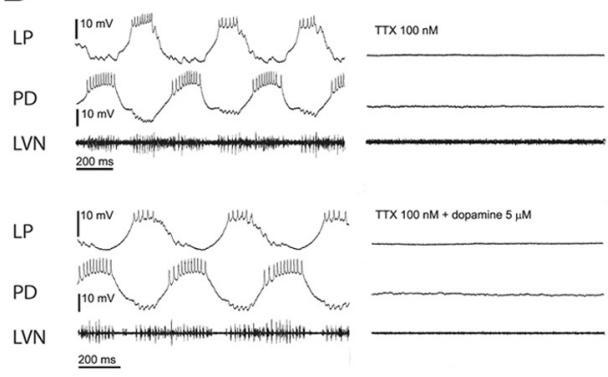

D

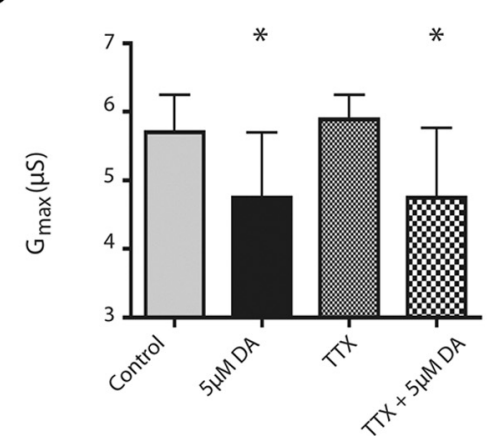

Figure 5. Blocking activity does not alter the persistent effects of $D A$ on $I_{A} \cdot \boldsymbol{A}$, Timelines for control and DA-treated experiments. One hundred nanomolar TTX was preadministered 10 min before time 0 , and then applied concurrently with DA administration (5 $\mu \mathrm{m})$ for $1 \mathrm{~h}$, or for $1 \mathrm{~h}$ with Panulirus saline in the control condition. In both cases, the preparation was then superfused with Panulirus saline for $3 \mathrm{~h}$. At time $4 \mathrm{~h}$, a sucrose block was applied to the stn and the STG was superfused with blocking saline for $1 \mathrm{~h}$. $I_{A}$ was then measured with TEVC. $B$, TTX blocks both spikes and voltage oscillations. Traces are representative intracellular and extracellular recordings in the absence (left) and presence (right) of TTX, under control (top) or DA (bottom) conditions. C, D, $D A$-induced changes are activity independent. Each bar represents the mean and SD for $n \geq 5$ experiments to measure $\operatorname{LP}(\boldsymbol{C})$ and $\operatorname{PD}(\boldsymbol{D}) I_{\mathrm{A}} G_{\max }$ in the indicated treatment groups. Data were analyzed with one-way ANOVAs followed by Dunnett's post hoc tests. * Significantly different from saline control. 

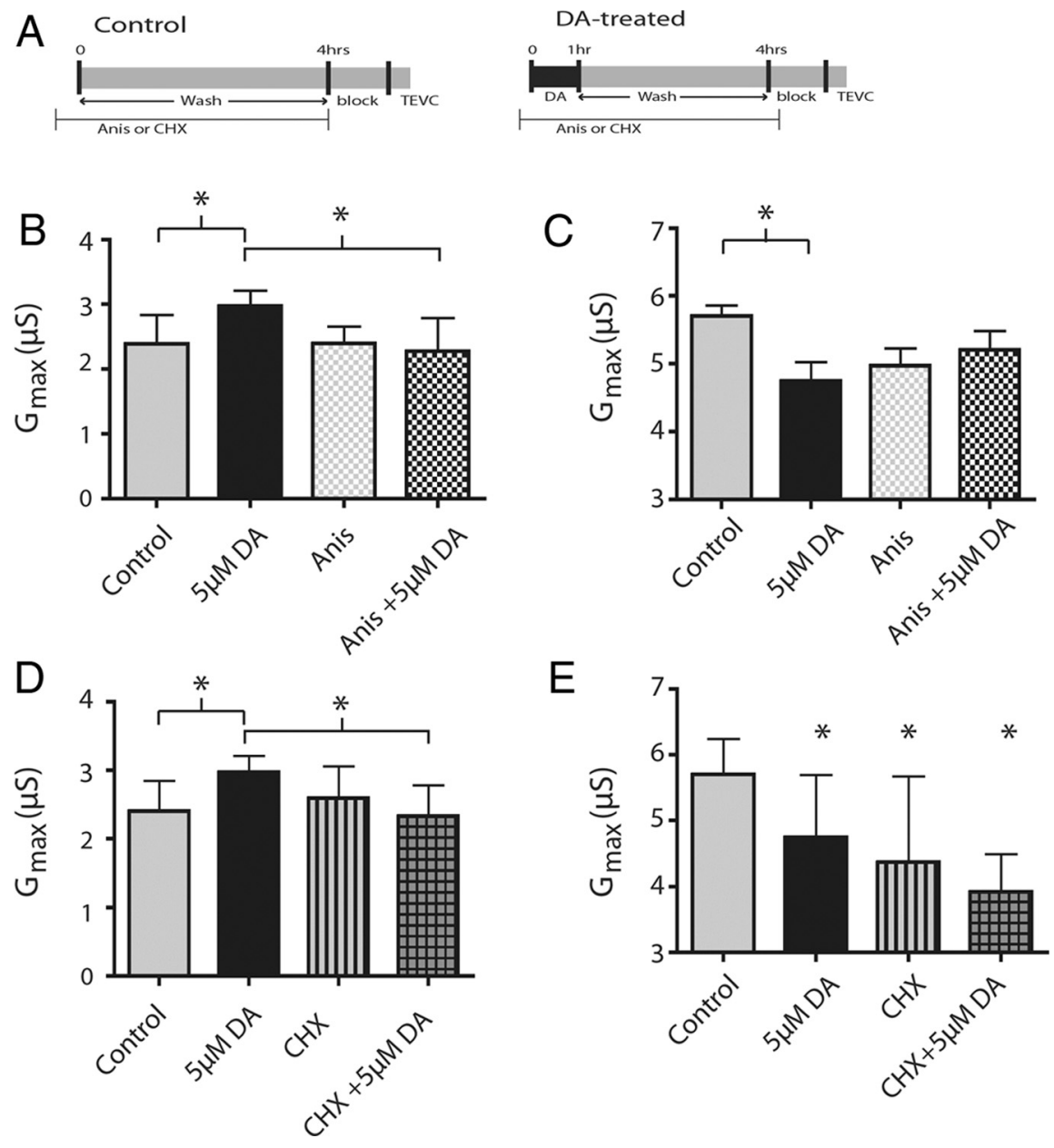

E
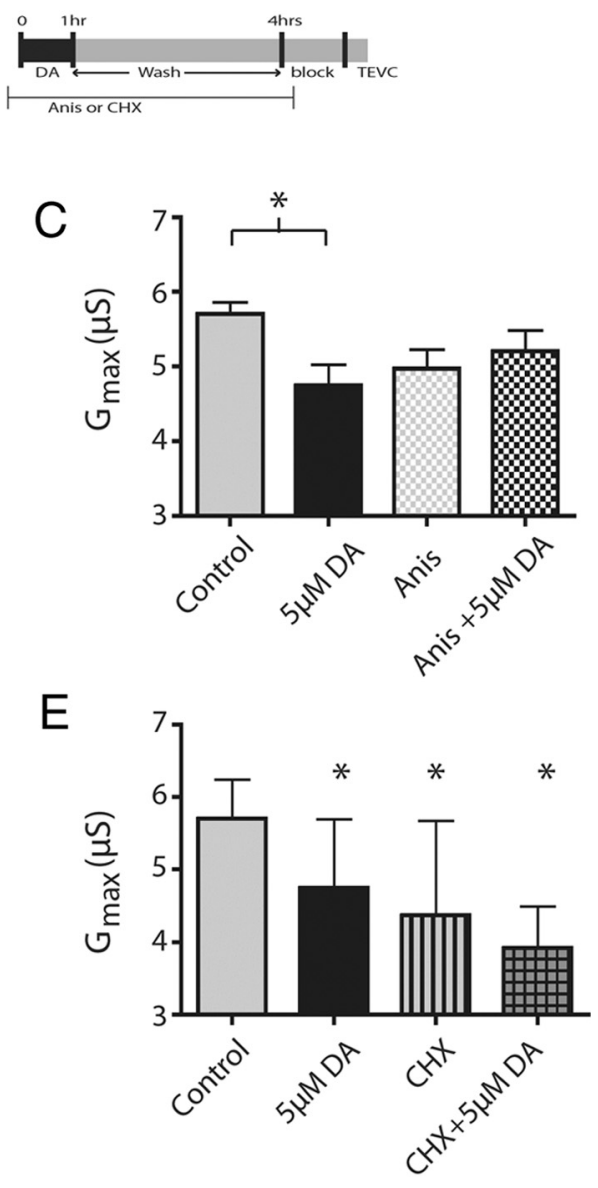

Figure 6. Translational inhibitors block or occlude persistent DA-induced changes in $I_{A} . \boldsymbol{A}$, Timelines of protein synthesis inhibitor administration in control and DA-treated experiments. Thirty micromolar Anis or $10 \mu \mathrm{M} C \mathrm{HX}$ was continuously applied starting 10 min before time 0 and ending at time $4 \mathrm{~h}$. In DA-treated experiments, $5 \mu \mathrm{m}$ DA was superfused from time $0-1 \mathrm{~h}$ followed by a $3 \mathrm{~h}$ wash with Panulirus saline. Controls were superfused with Panulirus saline from time $0-4 \mathrm{~h}$. At time $4 \mathrm{~h}$, the sth received a sucrose block and the STG was superfused with blocking saline for $1 \mathrm{~h}$, after which $I_{A}$ was measured with TEVC. $B, L P I_{A}$ $G_{\max }$ was compared using ANOVA between control, DA, Anis, and Anis + DA. DA was significantly different from control and Anis + DA (Tukey's post hoc test, $p<0.05) \cdot D, \mathrm{LPI}_{\mathrm{A}} G_{\max }$ was compared using ANOVA between controls, DA, cycloheximide using a one-way ANOVA with Tukey's post hoc tests. Post hoc analysis shows same pattern for CHX as Anis, with DA being significantly different from control and $\mathrm{CHX}+\mathrm{DA}$. Bars represent the means and SDs. $\boldsymbol{B}-\boldsymbol{D}$, *Significant differences between the bracketed groups. $\boldsymbol{C}, \boldsymbol{E}, P D I_{\mathrm{A}} G_{\max }$ was compared between Anis $(\boldsymbol{C})$ and $\mathrm{CHX}(\boldsymbol{E})$ using a one-way ANOVA with Tukey's post hoc tests ( ${ }^{*}$ significantly different from the saline control group). Anis blocks the DA effect, while $\mathrm{CHX}$ occludes the DA effect. Bars represent the means and $S D$ for $n \geq 5$ per treatment group.

$G_{\text {max }}\left(\right.$ ANOVA, $F_{(3,33)}=5.353, p=0.0041$; Dunnett's test, $p<0.05$ for DA and TTX + DA compared with saline control) (Fig. 5D). In neither PD nor LP were $I_{\mathrm{A}} G_{\max }$ values after TTX alone significantly different from saline control. These data suggest that DA-induced changes in $I_{\mathrm{A}} G_{\max }$ do not represent a homeostatic/compensatory response to DA-induced changes in target neuron activity, but may represent direct dopaminergic regulation of ion channel density. This is consistent with the fact that $5 \mathrm{nM}$ DA elicits a persistent change in $I_{\mathrm{A}} G_{\max }$, but does not change LP or PD activity (Flamm and Harris-Warrick, 1986).

\section{DA-induced changes in $I_{\mathrm{A}}$ are translation dependent}

The duration of the DA effect $(18+\mathrm{h})$ points toward a longlasting mechanism that may be protein synthesis dependent. To test this, we performed the $4 \mathrm{~h}$ experimental paradigm in the presence of the protein synthesis inhibitors Anis or CHX (Fig. $6 A$ ). Thirty micromolar Anis, applied throughout the experi- ment, was sufficient to block the DAinduced changes in LP $I_{\mathrm{A}} G_{\max }$ (ANOVA, $F_{(3,24)}=4.36, p=0.014$; Tukey's test, $p<$ 0.05 , control vs DA, DA vs Anis + DA) (Fig. 6B). Application of $10 \mu \mathrm{M} \mathrm{CHX}$, again given for the duration of the $4 \mathrm{~h}$ experiment (Fig. 6A), produced similar results in $\mathrm{LP}$ (ANOVA, $F_{(3,25)}=3.57, p=$ 0.028; Tukey's test, $p<0.05$, control vs DA, DA vs CHX + DA) (Fig. 6D). Neither Anis nor $\mathrm{CHX}$ alone significantly altered LP $I_{\mathrm{A}} G_{\max }(p>0.05$ Tukey's test, control vs Anis, control vs CHX).

Application of Anis or CHX to the STG appeared to occlude the effects of DA on PD $I_{\mathrm{A}} G_{\text {max }}$. Application of Anis, or Anis + DA nonsignificantly lowered $I_{\mathrm{A}} G_{\max }$ (Fig. $6 C)$ to an intermediate point between control and DA treated (ANOVA, $F_{(3,31)}=$ 3.540, $p=0.026$; Tukey's test, $p<0.05$ control vs DA, $p>0.05$ all other comparisons). $\mathrm{CHX}$ and $\mathrm{CHX}+\mathrm{DA}$ both significantly decreased $I_{\mathrm{A}} G_{\max }$ relative to controls (ANOVA, $F_{(3,31)}=7.27, p=0.0008$; Tukey's test, $p<0.05$, for all groups compared with saline control). CHX alone was not significantly different from $\mathrm{CHX}+\mathrm{DA}$, indicating that $\mathrm{CHX}$ occludes the DA-induced effect on $I_{\mathrm{A}}(p>$ $0.05)$. This suggests that the DA-induced effect on $P D I_{\mathrm{A}} G_{\max }$ is also translation dependent. Together, these data demonstrate that the DA-induced changes in $I_{\mathrm{A}} G_{\max }$ depend on translation in both cell types.

\section{Tonic DA does not regulate transcription of shal}

In pyloric neurons, $I_{\mathrm{A}}$ is mediated by ion channels in which the pore-forming subunits are encoded by the shal gene (Baro et al., 1997; Baro et al., 2000). To test whether persistent DA-induced changes in $I_{\mathrm{A}}$ were underpinned by changes in shal transcript numbers, we used a Taqman-based quantitative real-time PCR assay to compare shal expression in single LP and PD neurons between control and $5 \mu \mathrm{M} \mathrm{DA}$-treated preparations ( $4 \mathrm{~h}$ protocol) (Fig. 1). There were no significant differences in shal transcript number between control and $5 \mu \mathrm{M} \mathrm{DA}$-treated LP neurons ( $t$ test, $p>0.05$ ). No measurable differences in shal expression were detected between control and $5 \mu \mathrm{M}$ DA-treated PD neurons ( $t$ test, $p>0.05$ ).

We further asked whether the DA-induced changes in LP and PD $I_{\mathrm{A}} G_{\max }$ depended upon transcription of other proteins or small noncoding RNAs, by repeating the experiments while applying general transcription inhibitors (ACD or DRB) from -10 min to $1 \mathrm{~h}$ (data not shown). The results were equivocal. In our hands, the transcription inhibitors inconsistently altered control preparations and significantly increased variability, rendering the data uninterpretable. In sum, while DA does not persistently alter $I_{\mathrm{A}} G_{\max }$ at $4 \mathrm{~h}$ by altering shal transcript number, we cannot determine whether it acts by modifying the transcription/stability of non-shal transcripts. 
D1R-induced increases in $I_{\mathrm{A}}$ are TOR dependent

TOR is a serine/threonine kinase that regulates translation initiation (Hoeffer and Klann, 2010). Translation of dendritic Kv1.1 channel transcripts can be regulated by mammalian TOR (mTOR) (Raab-Graham et al., 2006), and mTOR can be regulated by DARs (Hoeffer and Klann, 2010). We tested whether TOR was involved in the DA-induced changes in LP and PD $I_{\mathrm{A}} G_{\max }$ by applying DA with the specific TOR inhibitor rapamycin (Fig. $7 A$ ). Rapamycin alone had no effect on LP $I_{\mathrm{A}}$, but it blocked the DA-induced increase in LP $I_{\mathrm{A}} G_{\max }$ (ANOVA, $F_{(3,25)}=5.259$, $p=0.006$; Dunnett's test, $p>0.05$ for rapamycin alone and rapamycin $+\mathrm{DA}$ compared with saline control) (Fig. $7 B$ ). These data provide additional support to the hypothesis that DA persistently increases $L P I_{\mathrm{A}}$ by regulating translation. In contrast, DA still decreased PD $I_{\mathrm{A}} G_{\max }$ in the presence of rapamycin (ANOVA, $F_{(3,34)}=5.371, p=0.0039$; Dunnett's post hoc test, $p<0.05$, DA and rapamycin + DA compared with saline control) (Fig. $7 C)$. Together, these data indicate that D1Rs increased $I_{\mathrm{A}} G_{\max }$ through a TORdependent mechanism, while D2Rs used an alternate translation-dependent pathway to decrease $I_{\mathrm{A}} G_{\max }$.

Tonic DA-induced changes in LP $I_{\mathrm{A}} G_{\max }$ do not produce the predicted alterations in pyloric motor output

We expected the significant changes in LP and PD $I_{\mathrm{A}}$ to have functional consequences. In this system, $I_{\mathrm{A}}$ influences cycle frequency, phase constancy, interspike interval and post-inhibitory rebound (PIR) (Tierney and Harris-Warrick, 1992; Hooper, 1997). We examined LP PIR in the three treatment groups. LP is rhythmically inhibited by the pacemaker kernel, which comprises the electrically coupled PD and anterior burster neurons. Upon release from inhibition, the LP neuron rebounds and fires a series of spikes on a depolarized plateau (Figs. $1 B, 5 B$ ). LP-on delay is measured as the time between the last PD spike and the first LP spike, and it reflects the rate of PIR. $I_{\mathrm{A}}$ helps determine LP-on delay (Tierney and Harris-Warrick, 1992), and in acutely isolated preparations LP shal transcript number linearly correlates with LP-on delay (Goaillard et al., 2009). A tonic DA-induced increase in $L P I_{\mathrm{A}} G_{\max }$ should reduce the rate of LP repolarization and increase LP-on delay. We measured LP-on delay in the experiments illustrated in Figure 1 at time 0 and $4 \mathrm{~h}$ for all three treatment groups (Fig. 8A). In contrast to the predicted increase in LP-on delay in the DA treatment groups, we found that LP-on delay had significantly decreased in the control and $5 \mathrm{~nm}$ treatment groups (Fig. $8 B$ ) (Student's $t$ test comparing LP-on delay at time 0 to $4 \mathrm{~h}$ for both treatment groups), and that there was no significant change in the $5 \mu \mathrm{M}$ DA treatment group (Student's $t$ test, $p>0.05$ ). These data suggested that tonic DA application may alter multiple conductances and that motor output was changing under control conditions, despite the presence of descending modulatory inputs.
DA-treated

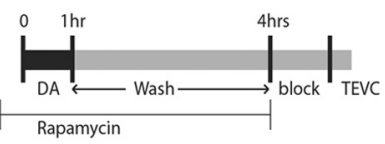

C

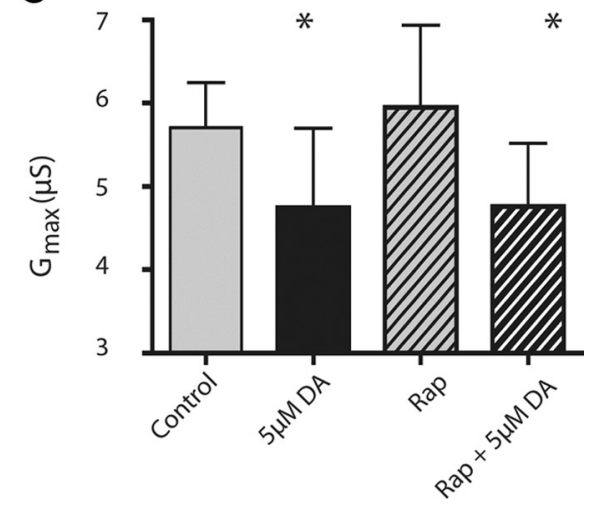

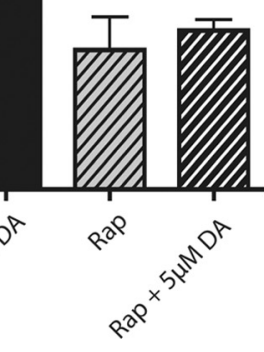

Figure 7. The persistent increase in $\mathrm{LP} I_{A}$, but not the persistent decrease in $P D I_{A}$ depends upon TOR. $A$, Timeline of rapamycin ) administration in control and $5 \mu \mathrm{M}$ DA-treated preparations: rapamycin (100 nM), a specific inhibitor of TOR, was applied Panulirus saline Controls were superfused with Panulirus saline from time 0 to $4 \mathrm{~h}$. At time $4 \mathrm{~h}$, the stn received a sucrose block and STTG was superfused with blocking saline for $1 \mathrm{~h}$, after which $/ A$ was measured with TEVC. $B$, Rapamycin blocked the DA-induced max Comparisons between groups were made using a one-way ANOVA with Dunnett's post hoc tests. $C$, ANOVA with Dunnett's post hoc tests. *Significant differences from saline control groups. Each bar represents the mean and SD for $n \geq 5$ for each treatment group.

\section{Discussion}

We have shown that DA can persistently alter voltage-gated ionic conductances through translation-dependent mechanisms in a manner that is independent of target neuron activity. A tonic $1 \mathrm{~h} \mathrm{D1R}$ activation produced a persistent $\sim 25 \%$ increase in LP $I_{\mathrm{A}} G_{\max }$ that was mediated by TOR. A tonic $1 \mathrm{~h}$ D2R activation persistently decreased $\mathrm{PD} I_{\mathrm{A}} G_{\max }$ by $\sim 20 \%$ through an unknown translation-dependent mechanism. In both cases, the persistent and immediate effects of DA on $I_{\mathrm{A}}$ were opposed. We speculate that steady-state $\mathrm{DA}$ could limit the effects of phasic DA on $I_{\mathrm{A}}$ and/or bias for or against specific synapses.

\section{Translational regulation of ion current densities}

Translational regulation of ion channel genes constitutes a critical mechanism for regulating plasticity and excitability (Weston and Baines, 2007). The complexity of translation provides several avenues for regulation, including the following: phosphorylation of proteins involved in translation initiation and elongation via TOR (Kelleher et al., 2004; Proud, 2007); microRNA translational suppression (Fabian et al., 2010); and regulating the availability of mRNA with RNA binding proteins such as the fragile X mental retardation protein (FMRP) (Weston and Baines, 2007; Richter, 2010) or the PUF family (Quenault et al., 2011).

D1Rs can regulate TOR activity (Schicknick et al., 2008; Santini et al., 2009) and alter the phosphorylation state of FMRP in the prefrontal cortex (Wang et al., 2010). To the best of our knowledge, this is the first study to demonstrate that tonic nanomolar DA can persistently regulate voltage-gated ion current densities through translation-dependent mechanisms. These findings are consistent with previous work showing that neuromodulators regulate ionic conductances over the long term in the STNS (Thoby- 
A Control

$5 \mathrm{nM}$ DA

$5 \mu \mathrm{M} \mathrm{DA}$

. nttht
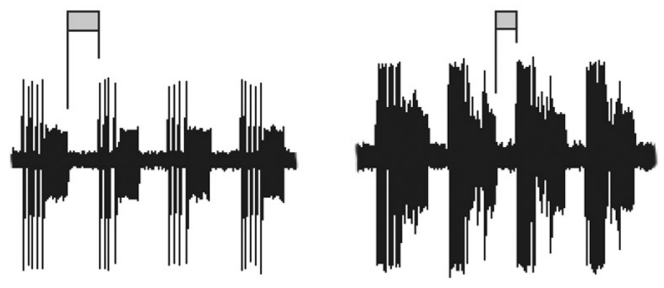

4 hours 1
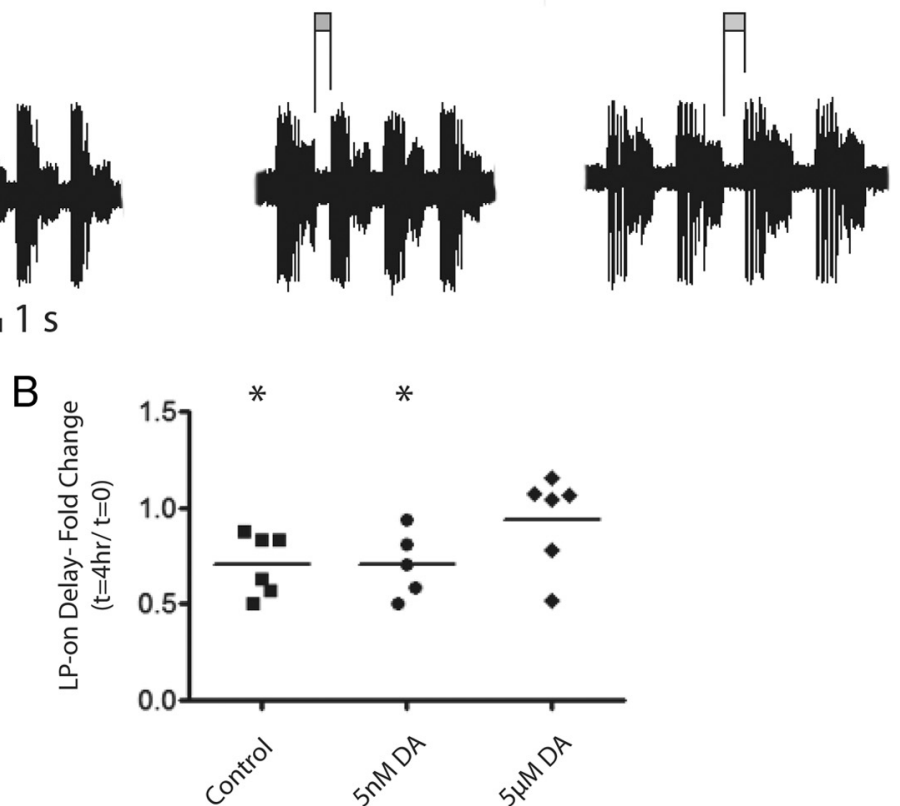

Figure 8. Increase in $L P I_{A} G_{\max }$ does not effect $L P$-on delay in the predicted manner. $A$, Representative extracellular traces from the /vn of control, $5 \mathrm{~nm}$, and $5 \mu \mathrm{m}$ DA at time 0 and $4 \mathrm{~h}$. LP-on delay was measured as the time between the last spike of the PD burst to the first spike of the LP burst, shown as a dark bar above the trace. The value shown is the average of 10 cycles. $\boldsymbol{B}$, Analysis of the normalized change in LP-on delay at the conclusion of the $4 \mathrm{~h}$ treatment. An increase in $I_{A}$ would be predicted to lengthen LP-on delay, which was not the case. Data in each treatment group were analyzed with a Student's $t$ test. *Significant difference between $t=0$ and $t=4 \mathrm{~h}$. Each symbol represents one experiment.

Brisson and Simmers, 2000; Mizrahi et al., 2001; Khorkova and Golowasch, 2007; Zhang et al., 2009; Zhao et al., 2010).

\section{Contrasts between immediate and persistent DA effects}

DA differentially modulates $I_{\mathrm{A}}$, and there are at least four important distinctions between its immediate and persistent effects. First, the immediate and persistent effects are opposed. Second, DA targets the following two different biophysical properties to bring about these effects: immediate changes rely largely on alterations in $I_{\mathrm{A}}$ voltage dependencies (Harris-Warrick et al., 1995b; Kloppenburg et al., 1999; Zhang et al., 2010); whereas persistent changes rely exclusively on alterations in $I_{\mathrm{A}} G_{\max }$. Third, the dose dependencies for the two effects differ by approximately three orders of magnitude for LP D1Rs. Fourth, immediate but not persistent effects were reversible under experimental conditions (Kloppenburg et al., 1999; Zhang et al., 2010).

\section{The magnitude and duration of the persistent effect}

We measured LP $I_{\mathrm{A}}$ acutely, after a $4 \mathrm{~h}$ wash (control), and after a $1 \mathrm{~h}$ DA treatment followed by a $3 \mathrm{~h}$ wash. Acute measures of LP $I_{\mathrm{A}}$ $G_{\max }$ ranged from 0.86 to $3.67 \mu \mathrm{S}(n=41)$, consistent with different combinations of synaptic and ionic conductances generating similar activity patterns (Marder and Taylor, 2011). Con- trol measures $(1.58-3.03 \mu \mathrm{S}, n=12)$ were not significantly different from acute, but LP $I_{\mathrm{A}} G_{\max }$ values in the $5 \mathrm{~nm}$ DA treatment group were skewed toward the upper limit of the physiological range (2.4$3.5 \mu \mathrm{S}, n=7)$. This TOR-dependent increase in $I_{\mathrm{A}} G_{\max }$ persisted for $>3 \mathrm{~h}$ but $<24 \mathrm{~h}$ after DA removal. It is not clear whether mechanisms to oppose the persistent actions of DA exist in vivo (e.g., other tonic modulators), and if so, whether they were present under our experimental conditions.

The time and concentration dependencies for both the duration and amplitude of the persistent effects of DA have not yet been determined. Duration varies with DA concentration: the effect of $1 \mathrm{~h}$ of $5 \mu \mathrm{M}$ DA persisted longer than that for $1 \mathrm{~h}$ of $5 \mathrm{~nm}$ DA. It is not clear whether amplitude varies with concentration as both 5 $\mathrm{nM}$ and $5 \mu \mathrm{M}$ DA produced the same persistent effect. It is not clear how the length of the DA application affects the duration or amplitude of the persistent response, as we did not vary the length of application. However, a 15 min exposure to D1/D5 agonist SKF-38393 $(100 \mu \mathrm{M})$ produced an increase in local protein synthesis (Smith et al., 2005).

A $1 \mathrm{~h}, 5 \mu \mathrm{M}$ DA application acted at both D1Rs and D2Rs to produce significant changes in $I_{\mathrm{A}} G_{\max }$ that persisted for $>24 \mathrm{~h}$ after DA removal. This application is not physiologically relevant, but was used to gain insight into the consequences of psychotropic drug consumption, which results in prolonged, elevated levels of DA (Frank et al., 2008). Long-lasting changes in neuronal excitability are a hallmark of drug addiction (Wolf, 2010). Since dopaminergic systems have been highly conserved across species, from modes of transmission through signaling cascades and even effects on final targets (Clark and Baro, 2006, 2007; Clark et al., 2008; Oginsky et al., 2010), our findings might suggest that persistent DA-induced changes in voltage-gated ion channel number may represent an initial step in the dynamic process leading to addiction.

\section{Do distinct DARs generate persistent versus immediate effects?}

High- and low-affinity D1Rs mediate persistent and immediate changes in LP $I_{\mathrm{A}}$, respectively. As in mammals, there are two crustacean D1Rs. $D_{1 \alpha \text { Pan }}$ receptors preferentially couple with Gs and $\mathrm{Gq}$ proteins, while $\mathrm{D}_{1 \beta \text { Pan }}$ receptors couple only with Gs (Clark et al., 2008). The immediate D1R-induced decrease in LP $I_{\mathrm{A}}$ is mediated through an increase in cAMP and PKA activity, which act to produce depolarizing shifts in the voltage dependence of activation and inactivation (Zhang et al., 2010). On the other hand, TOR mediates the persistent translation-dependent increase in LP $I_{\mathrm{A}} G_{\max }$. Both Gs- and Gq-coupled receptors have been shown to modulate TOR (Hoeffer and Klann, 2010). Thus, either or both D1Rs could mediate the immediate and/or persistent effects of DA on LP $I_{\mathrm{A}}$. When expressed in human embryonic 
kidney (HEK) cells, the DA EC ${ }_{50}$ values were $\sim 10^{-8}$ and $10^{-6}$ for $\mathrm{D}_{1 \alpha \text { Pan }}$ and $\mathrm{D}_{1 \beta \text { Pan }}$, respectively (Clark and Baro, 2006); however, these were based on CAMP assays and may not be accurate for D1Rs involved in the persistent response.

There is a single D2-like receptor in invertebrates, whose transcript is alternately spliced to create distinct isoforms with $\mathrm{DA} \mathrm{EC}_{50}$ values ranging from $\sim 10^{-6}$ to $10^{-8}$ when expressed in HEK cells (Hearn et al., 2002; Clark and Baro, 2007). D2Rs couple with Gi (Clark et al., 2008), but the cascades mediating the immediate and persistent changes in $\mathrm{PD} I_{\mathrm{A}}$ have not been determined. Since a given receptor can couple with multiple signaling cascades, and those cascades can change over time during continuous agonist application (Beaulieu and Gainetdinov, 2011), it is not clear whether the immediate and persistent responses are generated by the same or distinct receptor proteins.

\section{Localization of dopaminergic action}

Does DA act locally or globally to persistently regulate $I_{\mathrm{A}}$ ? In the STNS, both D1Rs and D2Rs are localized exclusively to terminals and/or synaptic structures on fine dendrites (Clark et al., 2008; Oginsky et al., 2010; Zhang et al., 2010). Calcium imaging studies have shown that the DA induced immediate increases (LP) or decreases (PD) in calcium are highly localized (Kloppenburg et al., 2000, 2007). It is not clear whether the changes in $I_{\mathrm{A}}$ we observe are similarly localized; however, previous work in other systems has shown that $I_{\mathrm{A}}$ density can be locally regulated (Losonczy et al., 2008; Makara et al., 2009), and that TOR can regulate translation of dendritic $\mathrm{K}^{+}$channels (Raab-Graham et al., 2006; Jiménez-Díaz et al., 2008). Further, neuromodulators have been demonstrated to locally regulate translation at specific synapses (Wang et al., 2009, 2010). These data raise the possibility that the persistent effects of DA are highly localized. Alternatively, high concentrations of DA $(100 \mu \mathrm{M})$ have been shown to increase somatic cAMP within minutes (Hempel et al., 1996). Thus, global regulation cannot be ruled out.

\section{Metaplasticity}

What is the purpose of tonic and phasic modulation of $I_{\mathrm{A}}$ in a single cell? Theoretically, DARs involved in tonic versus phasic modulation could be differentially localized and act on different subsets of ion channels. Alternatively, these two components could act together to generate metaplasticity (Abraham, 2008). Grace (1991) first proposed that exposing a cell to tonic DA could modulate that cell's response to phasic DA, and this idea has been borne out experimentally (Matsuda et al., 2006; Kolomiets et al., 2009; Kroener et al., 2009). The opposing actions of tonic and phasic DA may suggest that steady-state DA limits the effect of phasic DA. Due to volume transmission, as the activity of bursting dopaminergic neurons increases, local steady-state DA may also increase, thereby dampening further effects of phasic modulation. If true, this could represent a novel activity-dependent homeostatic mechanism to preserve target neuron activity within limits. This mechanism would compensate for changes in activity of the modulatory, not the target, neurons.

Additionally, or alternatively, tonic DA may serve in synapse selection. Tonic nanomolar peptide applications can weaken sensory modulation of a motor circuit (DeLong and Nusbaum, 2010). Similarly, tonic DA might bias for or against specific synapses, and phasic DA could transiently remove/ reverse that bias. PD D2Rs are found only at $40 \%$ of synaptic structures (Oginsky et al., 2010), suggesting that DARs may be localized to specific inputs/outputs, consistent with findings for nucleus accumbens neurons (Goto and Grace, 2005, 2008). This could provide a substrate for branch/synapse-specific changes in $I_{\mathrm{A}}$. Our working model is that tonic DA simultaneously weakens extrinsic excitatory inputs to branches/terminals containing D1Rs by increasing $I_{\mathrm{A}}$ to locally shunt synaptic currents, and strengthens inputs to D2R containing branches/ terminals by locally decreasing $I_{\mathrm{A}}$. Phasic DA would momentarily remove/reverse this bias. Since each synaptic structure in the STNS contains input and output elements (King, 1976), and pyloric neurons use graded synaptic transmission, tonic DA could also increase (D2Rs) and decrease (D1Rs) graded release at specific branches/terminals. Ultimately, the dopaminergic system could provide a mechanism for selecting specific inputs/outputs.

\section{References}

Abraham WC (2008) Metaplasticity: tuning synapses and networks for plasticity. Nat Rev Neurosci 9:387.

Baro DJ, Levini RM, Kim MT, Willms AR, Lanning CC, Rodriguez HE, HarrisWarrick RM (1997) Quantitative single-cell-reverse transcriptionPCR demonstrates that A-current magnitude varies as a linear function of shal gene expression in identified stomatogastric neurons. J Neurosci 17:6597-6610.

Baro DJ, Ayali A, French L, Scholz NL, Labenia J, Lanning CC, Graubard K, Harris-Warrick RM (2000) Molecular underpinnings of motor pattern generation: differential targeting of shal and shaker in the pyloric motor system. J Neurosci 20:6619-6630.

Beaulieu JM, Gainetdinov RR (2011) The physiology, signaling, and pharmacology of dopamine receptors. Pharmacol Rev 63:182-217.

Clark MC, Baro DJ (2006) Molecular cloning and characterization of crustacean type-one dopamine receptors: DlalphaPan and DlbetaPan. Comp Biochem Physiol B Biochem Mol Biol 143:294-301.

Clark MC, Baro DJ (2007) Arthropod D2 receptors positively couple with cAMP through the Gi/o protein family. Comp Biochem Physiol B Biochem Mol Biol 146:9-19.

Clark MC, Khan R, Baro DJ (2008) Crustacean dopamine receptors: localization and $\mathrm{G}$ protein coupling in the stomatogastric ganglion. J Neurochem 104:1006-1019.

DeLong ND, Nusbaum MP (2010) Hormonal modulation of sensorimotor integration. J Neurosci 30:2418-2427.

Dreyer JK, Herrik KF, Berg RW, Hounsgaard JD (2010) Influence of phasic and tonic dopamine release on receptor activation. J Neurosci 30:14273-14283

Fabian MR, Sonenberg N, Filipowicz W (2010) Regulation of mRNA translation and stability by microRNAs. Annu Rev Biochem 79:351-379.

Flamm RE, Harris-Warrick RM (1986) Aminergic modulation in lobster stomatogastric ganglion. I. Effects on motor pattern and activity of neurons within the pyloric circuit. J Neurophysiol 55:847-865.

Ford CP, Gantz SC, Phillips PE, Williams JT (2010) Control of extracellular dopamine at dendrite and axon terminals. J Neurosci 30:6975-6983.

Frank ST, Krumm B, Spanagel R (2008) Cocaine-induced dopamine overflow within the nucleus accumbens measured by in vivo microdialysis: a meta-analysis. Synapse 62:243-252.

Fuxe K, Dahlström A, Höistad M, Marcellino D, Jansson A, Rivera A, DiazCabiale Z, Jacobsen K, Tinner-Staines B, Hagman B, Leo G, Staines W, Guidolin D, Kehr J, Genedani S, Belluardo N, Agnati LF (2007) From the Golgi-Cajal mapping to the transmitter-based characterization of the neuronal networks leading to two modes of brain communication: wiring and volume transmission. Brain Res Rev 55:17-54.

Goaillard JM, Taylor AL, Schulz DJ, Marder E (2009) Functional consequences of animal-to-animal variation in circuit parameters. Nat Neurosci 12:1424-1430.

Goto Y, Grace AA (2005) Dopaminergic modulation of limbic and cortical drive of nucleus accumbens in goal-directed behavior. Nat Neurosci 8:805-812.

Goto Y, Grace AA (2008) Limbic and cortical information processing in the nucleus accumbens. Trends Neurosci 31:552-558.

Grace AA (1991) Phasic versus tonic dopamine release and the modulation 
of dopamine system responsivity: a hypothesis for the etiology of schizophrenia. Neuroscience 41:1-24.

Harris-Warrick RM, Coniglio LM, Barazangi N, Guckenheimer J, Gueron S (1995a) Dopamine modulation of transient potassium current evokes phase shifts in a central pattern generator network. J Neurosci 15:342-358.

Harris-Warrick RM, Coniglio LM, Levini RM, Gueron S, Guckenheimer J (1995b) Dopamine modulation of two subthreshold currents produces phase shifts in activity of an identified motoneuron. J Neurophysiol 74:1404-1420.

Harris-Warrick RM, Johnson BR, Peck JH, Kloppenburg P, Ayali A, Skarbinski J (1998) Distributed effects of dopamine modulation in the crustacean pyloric network. Ann N Y Acad Sci 860:155-167.

Hearn MG, Ren Y, McBride EW, Reveillaud I, Beinborn M, Kopin AS (2002) A Drosophila dopamine 2-like receptor: molecular characterization and identification of multiple alternatively spliced variants. Proc Natl Acad Sci U S A 99:14554-14559.

Hempel CM, Vincent P, Adams SR, Tsien RY, Selverston AI (1996) Spatiotemporal dynamics of cyclic AMP signals in an intact neural circuit. Nature 384:166-169.

Hoeffer CA, Klann E (2010) mTOR signaling: at the crossroads of plasticity, memory and disease. Trends Neurosci 33:67-75.

Hoffman DA, Johnston D (1999) Neuromodulation of dendritic action potentials. J Neurophysiol 81:408-411.

Hooper SL (1997) Phase maintenance in the pyloric pattern of the lobster (Panulirus interruptus) stomatogastric ganglion. J Comput Neurosci 4:191-205.

Jiménez-Díaz L, Géranton SM, Passmore GM, Leith JL, Fisher AS, Berliocchi L, Sivasubramaniam AK, Sheasby A, Lumb BM, Hunt SP (2008) Local translation in primary afferent fibers regulates nociception. PLoS One 3:e1961.

Johnson BR, Harris-Warrick RM (1990) Aminergic modulation of graded synaptic transmission in the lobster stomatogastric ganglion. J Neurosci 10:2066-2076.

Johnson BR, Peck JH, Harris-Warrick RM (1995) Distributed amine modulation of graded chemical transmission in the pyloric network of the lobster stomatogastric ganglion. J Neurophysiol 74:437-452.

Kelleher RJ 3rd, Govindarajan A, Tonegawa S (2004) Translational regulatory mechanisms in persistent forms of synaptic plasticity. Neuron 44:59-73.

Khorkova O, Golowasch J (2007) Neuromodulators, not activity, control coordinated expression of ionic currents. J Neurosci 27:8709-8718.

King DG (1976) Organization of crustacean neuropil. I. Patterns of synaptic connections in lobster stomatogastric ganglion. J Neurocytol 5:207-237.

Kloppenburg P, Levini RM, Harris-Warrick RM (1999) Dopamine modulates two potassium currents and inhibits the intrinsic firing properties of an identified motor neuron in a central pattern generator network. J Neurophysiol 81:29-38.

Kloppenburg P, Zipfel WR, Webb WW, Harris-Warrick RM (2000) Highly localized $\mathrm{Ca}^{2+}$ accumulation revealed by multiphoton microscopy in an identified motoneuron and its modulation by dopamine. J Neurosci 20:2523-2533.

Kloppenburg P, Zipfel WR, Webb WW, Harris-Warrick RM (2007) Heterogeneous effects of dopamine on highly localized, voltage-induced $\mathrm{Ca} 2+$ accumulation in identified motoneurons. J Neurophysiol 98:2910-2917.

Kolomiets B, Marzo A, Caboche J, Vanhoutte P, Otani S (2009) Background dopamine concentration dependently facilitates long-term potentiation in rat prefrontal cortex through postsynaptic activation of extracellular signal-regulated kinases. Cereb Cortex 19:2708-2718.

Kroener S, Chandler LJ, Phillips PE, Seamans JK (2009) Dopamine modulates persistent synaptic activity and enhances the signal-to-noise ratio in the prefrontal cortex. PLoS One 4:e6507.

Liss B (2002) Improved quantitative real-time RT-PCR for expression profiling of individual cells. Nucleic Acids Res 30:e89.

Losonczy A, Makara JK, Magee JC (2008) Compartmentalized dendritic plasticity and input feature storage in neurons. Nature 452:436-441.

Makara JK, Losonczy A, Wen Q, Magee JC (2009) Experience-dependent compartmentalized dendritic plasticity in rat hippocampal CA1 pyramidal neurons. Nat Neurosci 12:1485-1487.

Marder E, Bucher D (2007) Understanding circuit dynamics using the sto- matogastric nervous system of lobsters and crabs. Annu Rev Physiol 69:291-316.

Marder E, Taylor AL (2011) Multiple models to capture the variability in biological neurons and networks. Nat Neurosci 14:133-138.

Matsuda Y, Marzo A, Otani S (2006) The presence of background dopamine signal converts long-term synaptic depression to potentiation in rat prefrontal cortex. J Neurosci 26:4803-4810.

Mizrahi A, Dickinson PS, Kloppenburg P, Fénelon V, Baro DJ, HarrisWarrick RM, Meyrand P, Simmers J (2001) Long-term maintenance of channel distribution in a central pattern generator neuron by neuromodulatory inputs revealed by decentralization in organ culture. J Neurosci 21:7331-7339.

Musnier A, Blanchot B, Reiter E, Crépieux P (2010) GPCR signalling to the translation machinery. Cell Signal 22:707-716.

O’Dell TJ, Connor SA, Gelinas JN, Nguyen PV (2010) Viagra for your synapses: enhancement of hippocampal long-term potentiation by activation of beta-adrenergic receptors. Cell Signal 22:728-736.

Oginsky MF, Rodgers EW, Clark MC, Simmons R, Krenz WD, Baro DJ (2010) D(2) receptors receive paracrine neurotransmission and are consistently targeted to a subset of synaptic structures in an identified neuron of the crustacean stomatogastric nervous system. J Comp Neurol 518:255-276.

Panchin YV, Arshavsky YI, Selverston A, Cleland TA (1993) Lobster stomatogastric neurons in primary culture. I. Basic characteristics. J Neurophysiol 69:1976-1992.

Peck JH, Nakanishi ST, Yaple R, Harris-Warrick RM (2001) Amine modulation of the transient potassium current in identified cells of the lobster stomatogastric ganglion. J Neurophysiol 86:2957-2965.

Perez MF, White FJ, Hu XT (2006) Dopamine D(2) receptor modulation of $\mathrm{K}(+)$ channel activity regulates excitability of nucleus accumbens neurons at different membrane potentials. J Neurophysiol 96:2217-2228.

Proud CG (2007) Signalling to translation: how signal transduction pathways control the protein synthetic machinery. Biochem J 403:217-234.

Quenault T, Lithgow T, Traven A (2011) PUF proteins: repression, activation and mRNA localization. Trends Cell Biol 21:104-112.

Raab-Graham KF, Haddick PC, Jan YN, Jan LY (2006) Activity- and mTOR-dependent suppression of Kv1.1 channel mRNA translation in dendrites. Science 314:144-148.

Richter JD (2010) Translational control of synaptic plasticity. Biochem Soc Trans 38:1527-1530.

Santini E, Heiman M, Greengard P, Valjent E, Fisone G (2009) Inhibition of mTOR signaling in Parkinson's disease prevents L-DOPA-induced dyskinesia. Sci Signal 2:ra36.

Schicknick H, Schott BH, Budinger E, Smalla KH, Riedel A, Seidenbecher CI, Scheich H, Gundelfinger ED, Tischmeyer W (2008) Dopaminergic modulation of auditory cortex-dependent memory consolidation through mTOR. Cereb Cortex 18:2646-2658.

Schultz W (2007) Multiple dopamine functions at different time courses. Annu Rev Neurosci 30:259-288.

Schulz DJ, Goaillard JM, Marder E (2006) Variable channel expression in identified single and electrically coupled neurons in different animals. Nat Neurosci 9:356-362.

Selverston AI, Russell DF, Miller JP (1976) The stomatogastric nervous system: structure and function of a small neural network. Prog Neurobiol 7:215-290.

Shetreat ME, Lin L, Wong AC, Rayport S (1996) Visualization of D1 dopamine receptors on living nucleus accumbens neurons and their colocalization with D2 receptors. J Neurochem 66:1475-1482.

Smith WB, Starck SR, Roberts RW, Schuman EM (2005) Dopaminergic stimulation of local protein synthesis enhances surface expression of GluR1 and synaptic transmission in hippocampal neurons. Neuron 45:765-779.

Sossin WS, Lacaille JC (2010) Mechanisms of translational regulation in synaptic plasticity. Curr Opin Neurobiol 20:450-456.

Surmeier DJ, Ding J, Day M, Wang Z, Shen W (2007) D1 and D2 dopaminereceptor modulation of striatal glutamatergic signaling in striatal medium spiny neurons. Trends Neurosci 30:228-235.

Thoby-Brisson M, Simmers J (2000) Transition to endogenous bursting after long-term decentralization requires de novo transcription in a critical time window. J Neurophysiol 84:596-599. 
Tierney AJ, Harris-Warrick RM (1992) Physiological role of the transient potassium current in the pyloric circuit of the lobster stomatogastric ganglion. J Neurophysiol 67:599-609.

Wang DO, Kim SM, Zhao Y, Hwang H, Miura SK, Sossin WS, Martin KC (2009) Synapse- and stimulus-specific local translation during longterm neuronal plasticity. Science 324:1536-1540.

Wang H, Kim SS, Zhuo M (2010) Roles of fragile X mental retardation protein in dopaminergic stimulation-induced synapse-associated protein synthesis and subsequent alpha-amino-3-hydroxyl-5-methyl-4isoxazole-4-propionate (AMPA) receptor internalization. J Biol Chem 285:21888-21901.

Weston AJ, Baines RA (2007) Translational regulation of neuronal electrical properties. Invert Neurosci 7:75-86.

White RJ, Sharrocks AD (2010) Coordinated control of the gene expression machinery. Trends Genet 26:214-220.

Wong AC, Shetreat ME, Clarke JO, Rayport S (1999) D1- and D2-like dopamine receptors are co-localized on the presynaptic varicosities of striatal and nucleus accumbens neurons in vitro. Neuroscience 89:221-233.

Yao WD, Spealman RD, Zhang J (2008) Dopaminergic signaling in dendritic spines. Biochem Pharmacol 75:2055-2069.

Zhang H, Rodgers EW, Krenz WD, Clark MC, Baro DJ (2010) Cell specific dopamine modulation of the transient potassium current in the pyloric network by the canonical $\mathrm{d} 1$ receptor signal transduction cascade. J Neurophysiol 104:873-884.

Zhang Y, Khorkova O, Rodriguez R, Golowasch J (2009) Activity and neuromodulatory input contribute to the recovery of rhythmic output after decentralization in a central pattern generator. J Neurophysiol 101:372-386.

Zhao S, Golowasch J, Nadim F (2010) Pacemaker neuron and network oscillations depend on a neuromodulator-regulated linear current. Front Behav Neurosci 4:21.

Zoli M, Torri C, Ferrari R, Jansson A, Zini I, Fuxe K, Agnati LF (1998) The emergence of the volume transmission concept. Brain Res Brain Res Rev 26:136-147. 